International Journal of Engineering \& Technology, $7(3.30)(2018) 237-241$
SPC
Website: $w$ ww.sciencepubco.com/index.php/IJET
Research paper

\title{
The Introduction to Self-Reflection through Sociolinguistics
}

\author{
Norshima Zainal Shah $^{1 *}$, Amnah Saayah Ismail ${ }^{2}$, Norlela Samad ${ }^{3}$ \\ ${ }^{1}$ Language Centre, Universiti Pertahanan Nasional Malaysia \\ ${ }^{2}$ Faculty of Defence Studies and Management, Universiti Pertahanan Nasional Malaysia \\ ${ }^{3}$ Institute of Diplomacy and Foreign Relations, Ministry of Foreign Affairs, Kuala Lumpur, Malaysia \\ *Corresponding author E-mail: shima@ upnm.edu.my
}

\begin{abstract}
Reflection is a powerful thinking tool. This action research aims to introduce reflective thinking to 32 students undertaking the Sociolinguistics course. The students were introduced to seven selected teaching activities such as using short stories, writing journal article review, writing a report after an interview and producing a video, to name a few during the course. At the same time, the students were exposed to a series of reflective thinking activity following the Model of Holistic Reflection. They consistently wrote about their reflections and answered a questionnaire on their learning experience. The planned activities gave the students a chance to put sociolinguistics theory into practice and was most apparent in the activity of interviewing a friend of another ethnicity and producing a short video where both activities were rated as the most liked and enjoyable activity in the course. The students proposed several interesting alternatives to make lessons better according to their preferences. Overall, through reflective thinking, the students demonstrated their ability to transform what they have learned into everyday practice. Additionally, the lecturer also benefited from students' feedback in planning and improving the course. More invaluable data can be obtained in utilising the methodology used in this study to teach other courses in the future.
\end{abstract}

Keywords: Learning Experience, Reflection, Reflective Thinking, Sociolinguistics, the Holistic Reflection Model

\section{Introduction}

Several authors have highlighted the need to encourage students to engage in self-reflection as students learn better from their own experiences in preparation for a high-quality professional practice $[1,2,3]$. When students are provided with opportunities to examine and reflect upon their beliefs, philosophies and practices, and deconstruct prevailing ideologies, they are more likely to see themselves as active change agents and lifelong students within their professions [4] and this leads to positive changes in attitude and future behaviour [5]. It is also said that self-reflection can be regarded as a means of improving students' lifelong learning and professional practice in higher education [6]. Bain et al. [7] argued that deep reflective skills can be taught; however, they require development and practice over time. Ertmer and Newby (1996) postulated reflection as an active process of making sense of past experiences for the purpose of orientating oneself for current and/or future thought and action. The second viewpoint assumes reflection as a process of managing and adjusting the progress of learning whilst it is taking place. In addition, Boud et al. [1] recognised reflection as an essential element of experiential learning and included the act of thinking about what one has learned, as well as how one has learned it, in their model of the reflective process. Their conceptualisation included a series of stages such as looking back on experiences, attending to feelings, recognising values and beliefs, underlying actions and decisions, considering consequences and implications, exploring alternatives and reconsidering former views. Writing reflections down as said by Bolton
[9] leaves footsteps which aids progressive thoughts; in the sense that what has been written can be stored, read, and re-read and shared with colleagues. It is important then to write even if no one will ever read what is being written. It is the process of writing which helps us to reflect: to consider the value of our experiences and what we can learn from them. Reflective practice oriented online discussion can yield positive outcomes on reflective practice, and even seem to develop social interactions between participants.

This action research was designed to give students the opportunity to learn how to reflect through several planned activities in the Sociolinguistics course by adapting the Holistic Reflection Model.

\section{Review of Literature}

\subsection{The Holistic Reflection Model}

This model uses six integrated, inter-dependent phases designed to promote detailed critical reflection at a deeper personal and holistic level as students progress through the programme [10]. The six phases of reflection is simplified in Table 1 below.

\subsection{Sociolinguistics}

This course is an introduction to the relationship between society and language. The students were exposed to the study of languages and how language varies through social class, ethnicity, gender, nation, identity, geography, and cultures. This course also encourages students to further develop their critical thinking abil- 
ity by applying certain knowledge gained throughout the course to the language that they are learning, and examine the language sensitivity aspects and the ways languages are used. It carries 4 credit value and was taught over a period of 14 weeks.

\subsection{Teaching Activities}

There were seven planned teaching activities used in this course. They are: 1. Using short stories for Introduction, 2. Writing a journal article review, 3. Writing a report after interviewing a friend of a different ethnicity, 4. Producing a video on sociolinguistics issues e.g. language differences according to gender, 5 . Using Power Point for group presentation, 6. Using the university's Learning Management System (LMS), and 7. Short written tests after each topics.

Table 1: Explanation on Model of Holistic Reflection

\begin{tabular}{|c|c|c|}
\hline Phase & Guideline & Note \\
\hline Phase One & $\begin{array}{l}\text { Students are encouraged to maintain an open mind and } \\
\text { capture their thoughts, emotions and responses during } \\
\text { their experience in learning the course. }\end{array}$ & $\begin{array}{l}\text { Students are explained in detail what they are going to expe- } \\
\text { rience; that the course will use a number of teaching method- } \\
\text { ologies, that they are expected to write their thoughts and } \\
\text { emotions after every class, that no response is a wrong re- } \\
\text { sponse and they are free to jot down their feelings, things that } \\
\text { appear to be significant at that time. }\end{array}$ \\
\hline Phase Two & $\begin{array}{l}\text { Students are encouraged to write a detailed description } \\
\text { of their learning experience. }\end{array}$ & $\begin{array}{l}\text { Students write on their class experience, what they know of } \\
\text { the topic before and after the lesson, how they have enjoyed } \\
\text { doing the activities. Free writing without analysing them. }\end{array}$ \\
\hline Phase Three & $\begin{array}{l}\text { Students are required to explore in greater depth and } \\
\text { breadth their thoughts, feelings, and actions of them- } \\
\text { selves and others. }\end{array}$ & $\begin{array}{l}\text { Learner write on their own experience and get to read friends' } \\
\text { responses and comment on friends' responses. This includes } \\
\text { examining underpinning values, beliefs and assumptions re- } \\
\text { lated to the process of learning and teaching to develop criti- } \\
\text { cal reflection. Students begin to make sense of whole experi- } \\
\text { ence. }\end{array}$ \\
\hline Phase Four & $\begin{array}{l}\text { Students are encouraged to draw diverse ways to ex- } \\
\text { plore their learning experience in a holistic manner. }\end{array}$ & $\begin{array}{l}\text { Students write what happened in their learning and what are } \\
\text { the factors which contributed to the outcome of learning } \\
\text { through multiple lenses. }\end{array}$ \\
\hline Phase Five & $\begin{array}{l}\text { Students are required to engage themselves in an evalu- } \\
\text { ative process. Objectively stepping back from the event } \\
\text { and critically analysing in-depth aspects of own experi- } \\
\text { ence, what went well, what did not, and how things } \\
\text { could be done differently in the future using a solution- } \\
\text { focused approach. }\end{array}$ & $\begin{array}{l}\text { Students are encouraged to be truthful about their learning } \\
\text { experience which include what they like or did not like about } \\
\text { the course or comment about the way the course was con- } \\
\text { ducted, and how they want it differently. }\end{array}$ \\
\hline Phase Six & $\begin{array}{l}\text { Students are prompted into the transformational learn- } \\
\text { ing phase where they identify how they will translate } \\
\text { their learning experience into their everyday practice in } \\
\text { becoming a reflective practitioner. }\end{array}$ & $\begin{array}{l}\text { Learners write to reflect their experience, what has the course } \\
\text { taught them, what actions do they plan to take forward, how } \\
\text { has the course transformed their personal perspectives. }\end{array}$ \\
\hline
\end{tabular}

Adapted from the Bass Model of Holistic Reflection: students guidelines and prompts [10].

\section{Method}

\subsection{Samples}

The samples consisted of students in a 3-year Social Science programme, taking the Sociolinguistics (LSS1244) course. All 32 of them (3 males and 29 females) participated in this study.

\subsection{Data Collecting Instrument}

The 11-item questionnaire used was solely constructed for this study. It has 8 straightforward questions where students were offered a choice of ten or five pre-coded responses. For question 1, the pre-coded responses are "I do not understand at all what was taught (0)" to "I understand thoroughly what was taught (10)."

\begin{tabular}{|c|c|c|c|c|c|c|c|c|c|c|}
\hline 0 & 1 & 2 & 3 & 4 & 5 & 6 & 7 & 8 & 9 & 10 \\
\hline $\mathrm{O}$ & $\mathrm{O}$ & $\mathrm{O}$ & $\mathrm{O}$ & $\mathrm{O}$ & $\mathrm{O}$ & $\mathrm{O}$ & $\mathrm{O}$ & $\mathrm{O}$ & $\mathrm{O}$ & $\mathrm{O}$ \\
\hline Do not understand at all & & & & $\begin{array}{l}\text { Neither } \\
\text { understand } \\
\text { nor don't }\end{array}$ & & & & $\begin{array}{l}\text { Extremely } \\
\text { understand }\end{array}$ \\
\hline
\end{tabular}

\begin{tabular}{|c|c|c|c|c|}
\hline 1 & 2 & 3 & 4 & 5 \\
\hline $\mathrm{O}$ & $\mathrm{O}$ & $\mathrm{O}$ & $\mathrm{O}$ & $\mathrm{O}$ \\
\hline dislike extremely & dislike very much & neither like nor dislike & like very much & like extremely \\
\hline
\end{tabular}

For the following seven questions, Questions 2-8 asked students to reflect on how efficient or inefficient was the teaching and learning methodology/ activities brought to the classroom, as stated above. The Likert Scale used has five (5) pre-coded responses with the neutral point being neither "I dislike extremely this activity" nor "I like extremely this activity." A five point Likert scale was used which measures both directions (favourable and nonfavourable) and degree (how favourable and how non-favourable). Next are questions 9 to 11 . They are open-ended questions allowing students again to reflect and open up to what they found to be most interesting about the course, most daunting (least interesting) aspect of the course, how they would improvise the course, and 
their overall reflection after completing the course. Students were coaxed to write more than five (5) sentences for each question.

\subsection{Analysis of Data}

Data were analysed using descriptive statistics and content analysis. Firstly, descriptive statistics in graphical form that is bar chart which were summarised automatically by Googleform. From the percentages of students' choices, we can see whether students favour most or least the activities conducted throughout the course. Secondly, thematic analysis was used to examine the qualitative data. Theme within data becomes the categories for analysis. The purpose of thematic analysis is to identify patterns of meaning across a dataset that provide an answer to the research question being addressed. Thematic analysis suits questions related to people's experiences, or people's views and perceptions.

\section{Findings and Discussion}

The findings, followed by discussion are given according to the phases in the Model of Holistic Reflection.

\subsection{Phase One}

The question, "What is sociolinguistics?" produced many responses but, obviously, at the beginning of the semester, on the first day of class, students have a little to zero knowledge about the course, and for some, it was their first time hearing the word "sociolinguistics".

Hmmm ... no idea.

I don't have a clue.

Learning about language and society?

Socio from social linguistics something to do with language...

It was obvious that it is an entirely new course for the students, and students are not afraid to admit that they do not know about the course. A few students could make intelligent guesses about the word. Just asking them to think about the name of the course ignited curiosity and was seen as a good way to start off the course.

\subsection{Phase Two}

Firstly, students were asked to rate on a scale of 10 , their understanding of Sociolinguistics.

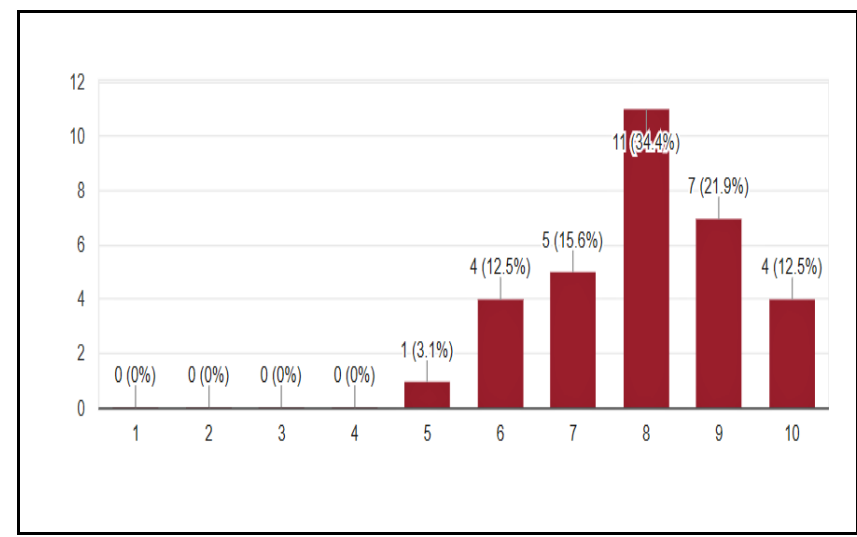

Fig. 1: Understanding of Sociolinguistics

Basically, 31 students showed understanding of Sociolinguistics. The bar chart shows that 11 out of 32 had extreme understanding while 20 had good understanding and 1 student neither understand nor do not understand the course.
Secondly, students were asked to reflect and rate how much they liked doing the activities throughout the Sociolinguistics course. Figure 2 shows students' two most liked activities out of the seven activities.

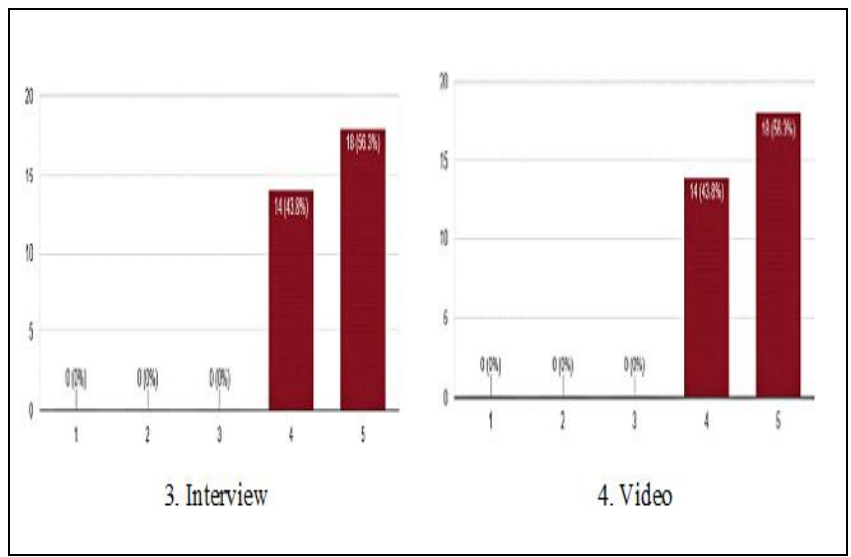

Fig. 2: Two most liked activities in Sociolinguistics

Activities 3 and 4 were found to be students' favourite: 3 . Writing a report after interviewing a friend of a different ethnicity and 4. Producing a video on a sociolinguistics issue e.g. language differences according to gender. Why are these two activities more favourable to students? Students were seen to favour activities which give them freedom and are more challenging. They worked better when they have the liberty to choose and work on their own, to be creative especially in utilising available technology to complete the tasks given to them.

\subsection{Phase Three}

The class has a group on Facebook where the lecturer used it as a means of communicating with students such as posting latest issue on Sociolinguistics or simply keeping in touch. In one of the topics, students were asked to apply a Socioliguistics theory to the things they experienced in everyday life and come up with short videos, and post the videos on Facebook. The students were also given the chance to write their own comments on the videos they produced, watch other people's video, read the comments and leave responses to the videos or comments.

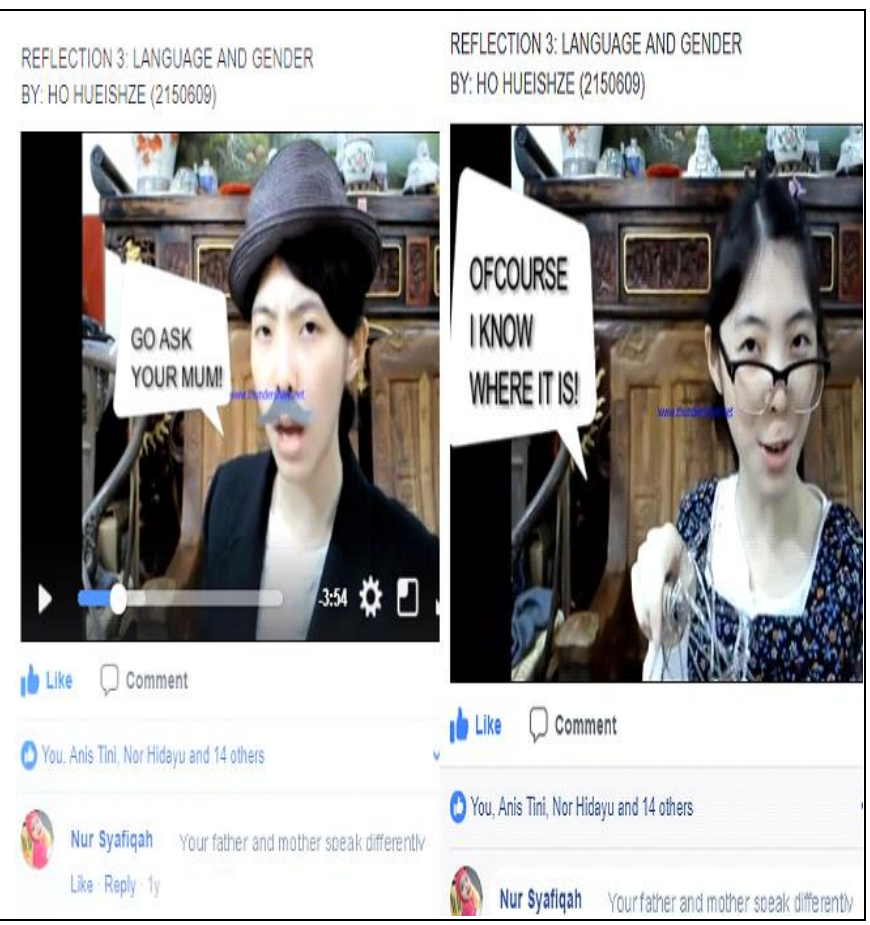

Fig. 3: A snapshot of a student's video and comments 
Examples of students' exchanges in the comments as in the figure above:

$\begin{array}{ll}\text { Nur Syafiqah } & \text { Your father and mother speak differently } \\ \text { Yannise Yan } & \text { Their tone is different } \\ \text { Nor Hidayu } & \text { Sweet your mother } \\ \text { Nur Syafiqah } & \text { Men only speak a little, like my father }\end{array}$

Students were given the opportunity to explore in greater depth and breadth of their thoughts, feelings, and actions of themselves and others. In developing critical reflection, the students began to see how theory relates to real life and they were able to relate their own experience, share with friends, justify behaviours, listen and accept friends' point of view. Through the opportunity to comment on Facebook, students were exposed to social interaction through a sort of online forum.

\subsection{Phase Four}

Using Padlet, the students wrote what happened in their learning and what were the factors which contributed to the outcome of learning through multiple lenses. They used theories that had been taught to them to justify their understanding. Students reflected on their learning experience, shared their learning experience and concluded what were the factors that contributed to their learning outcomes.

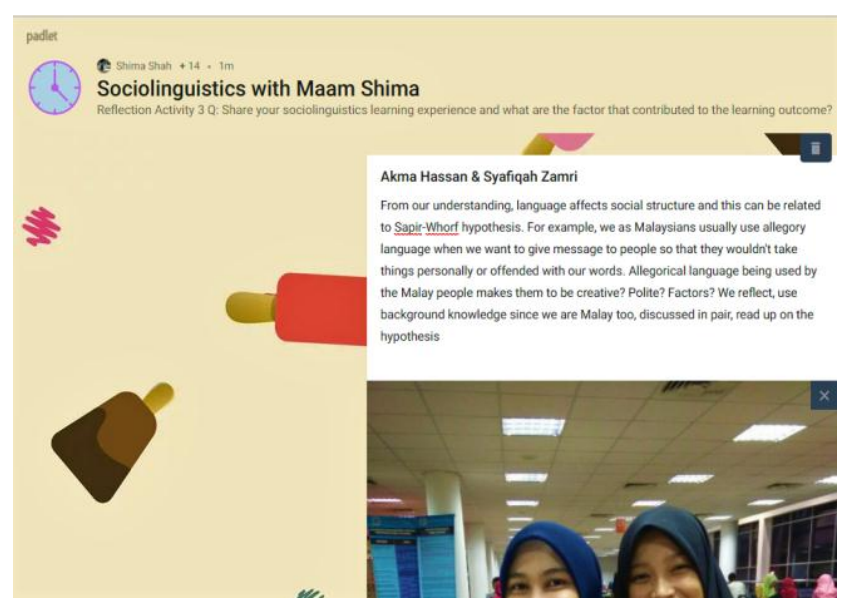

Students are encouraged to draw diverse ways (their background knowledge, what they have learnt, further readings on topics, own culture or experiences) to explore their learning experiences in a holistic manner. As it was a 'pair work' activity, students firs exchange ideas with their partners/pairs; followed by discussion with fellow classmates on padlet. This activity again creates an online discussion forum where students' reflection could be shared by other students.

\subsection{Phase Five}

For phase five, students were asked what they find most interesting, most daunting about the course and suggestions to make the course better. All answers can be summed up into two categories: the course and lecturer. Students claimed that Sociolinguistics is something new to them so they gained new knowledge. They also commented on lecturer's way of conducting the class, her motivation, her kindness towards them and her fluency in language which made the course interesting to them. Some of the comments are:

The course is interesting because it increases my understanding about the languages that are being used in the society.

I learned about English varieties, dialects, pidgin, creole, regis ter and code switching, which are all new to me and interesting.
Your way of treating us, never scolded us like kids, gave us enough time to complete our work, being with us like a mother; sometimes you brought us home cooked food.

Secondly, when students were asked about what they dislike about the course, they spoke of the course, the activities, and the class. Students lamented that they found the theories difficult to understand, topics are hard and sometimes too much information for them to digest. They tried to find reading materials to deepen their understanding but resources are limited. One respondent wrote of not being able to see the connection between what he is learning to future employment. In addition, many wanted field trip as one of the activities. Another respondent spoke of being sleepy since class is conducted in the evening.

Test suddenly. Some topics are too hard to understand. Some times we sleep in class. Sometimes the environment makes us feel sleepy. No activity outside the class.

It's hard to find the resources if we don't know how to find it. We also could find the same thing as others and it's hard to be different from others.

The subject is not really relevant to my career. Furthermore, I don't use it in my field work. The subject is realistic to those who are involved with society.

Sometimes the topic is complicated to understand. The answers are sometimes confusing. There are some of the answers of the question quite same.

The class period is not suitable which is in the evening that makes me feel sleepy.

Lastly, there are not many suggestions on how to make the course better or more interesting from students since mostly wrote they are happy with the class. Nevertheless, they named a few other alternative activities which included field trips, singing, drama, and online games such as kahoot.

In my humble opinion, the course will be more interesting if we can move out from the classroom and do something practi cal such as field trip to foreigners-focused place, pay a visit to other universities or even watch an educational movie. The suggestions above can give students the opportunity to apply the theories that they have learnt in class. It's always more interesting than sitting in the classroom.

Do a lot of kahoot quiz after we had learned one topic. Play game using tic tac toe which is the question are about what we had learn.

Create a drama like what we had done in oral com munication course. Do explorace.

Perhaps we can do field trip $\odot \square$

Here, students are required to engage themselves in an evaluative process. They are seen as objectively stepping back from the event and critically analysing in-depth aspects of own experience, what went well, what did not, and how things could be done differently in future. This is where the lecturer can discover many things especially how the students 'feel' being in his/her class.

\subsection{Phase Six}

In this phase, students reflect on what has been taught to them and whether aspects of the course are applicable to their everyday life. Responses denote what students thought about how the course had or will affect them: 
Learning about other culture. Knows better about lifestyle. Studying different view of language. Knowing existence of languages. Basic skills of speaking.

This course give me chance to gain more knowledge about others, especially through the activity of interviewing another person from another ethnicity. It made me realise that we are a multiracial country and this course helps me to respect others.

I can discover that I can adapt to one language has many varia tions. Such as different slang and dialects. Next, gender and language have many differences, so I learn to understand men more after learning this course $>_{-}<$. Lastly, it gives me more interesting feeling when I speak, because I have learnt what language is about.

The course is interesting because it boost my understanding about the languages that being used in society. English variety, dialect, pidgin, creole, register and code switching are very interesting to learn. Besides, I would like to discover more on the languages used between different registers and different genders.

The knowledge of sociolinguistics help me to learn more on how to communicate with different people. It allow me to communicate appropriately and easily to gain understanding while communicate with others.

Students were prompted into the transformational learning phase where they identify how they will translate their learning experience into their everyday practice in becoming a reflective practitioner. In addition, it is sound to say that students had enjoyed the Sociolinguistics course, learned new knowledge and are able to apply what they have learned to everyday life. Most importantly, they learned how to reflect.

\section{Conclusion}

The Sociolinguistics course went well by drawing up the Model of Holistic Reflection and thinking of the activities suited to teach each topic in the course. It was apparent that students were engaged in self-reflection while doing the activities. Students did all the reflective activities without knowing a study was being conducted. By doing the reflective thinking activities students were not only stimulated to think but they were also aware of the learning that has taken place and this reinforced what has been taught. In conclusion, much can be achieved when students reflect. For one, the lecturer is conscious of what is happening in the classroom; whether students comprehend the lessons, find the lessons boring, etc. to take appropriate steps to improvise the lessons for the benefit of the students. It is also possible to apply the model to other courses with the possibility of varying the activities.

\section{References}

[1] Boud D, Keogh R \& Walker D (Eds) (1985), Reflection: turning experience into learning. London: Kogan Page.

[2] Moon J (1999), Reflection in Learning and Professional Development: Theory and Practice. Exeter: Psychology Press. ISBN074943452X, 9780749434526

[3] Westberg J \& Jason H (2001), Fostering reflection and providing feedback: helping others learn from experience. New York: Springer.

[4] Mezirow J (1990), Fostering critical reflection in adulthood. San Francisco: Jossey-Bass. 2006. An overview of transformative learning. In Lifelong Learning, edited by P. Sutherland and J. Crowther. London: Routledge.

[5] Grant MJ (2007), The role of reflection in the library and information sector: a systematic review. Health Information and Libraries Journal 24, 155-166.
[6] Rogers RR (2001), Reflection in Higher Education: A Concept Analysis. Innovative Higher Education, 26: 37.

[7] Bain JD, Ballantyne R, Mills C \& Lester NC (2002), Reflecting on practice: Student teachers' perspectives. Flaxton: Post Pressed.

[8] Ertmer PA \& Newby TJ (1996), The Expert Learner: Strategic, Self-Regulated, and Reflective. Instructional Science, 24:1-24.

[9] Bolton G (n.d), Writing as a Reflective Practitioner with Wisdom. Available from: www.shef.ac.uk/uni/projects/wrp/rpwrite.html (Accessed 20 February 2018)

[10] Bass J, Fenwick J \& Sidebotham M (2017), Development of a Model of Holistic Reflection to facilitate transformative learning in student midwives, In Women and Birth, 30(3), 227-235, ISSN 1871-5192, https://doi.org/10.1016/j.wombi.2017.02.010 http://www.sciencedirect.com/science/article/pii/S18715192173007 $7 \mathrm{X}$. 